\title{
Oculomotor dysfunction in patients with syphilis
}

\author{
ULF ROSENHALL,* GUN-BRITT LÖWHAGEN, † AND GÖSTA ROUPE † \\ From the Departments of *Audiology and †Dermatology, University of Göteborg, Sahlgren's Hospital, \\ Göteborg, Sweden
}

SUMMARY Four patients with syphilis or, in two instances, possibly some other treponematosis, underwent oculomotor and audiological tests. The oculomotor test result was abnormal in all four patients. Three had abnormal smooth pursuit eye movements and two of them had hypometric voluntary horizontal saccades, which indicate that the central nervous system (CNS) was affected. Moreover, one of the patients had pathological auditory brain stem responses, which indicate brain stem dysfunction. Another patient had signs of Menière's syndrome in one ear.

\section{Introduction}

Neurosyphilis has become rare since the introduction of penicillin to syphilis treatment. According to some authors the clinical picture of neurosyphilis has changed, and in their opinion there is an increased incidence of atypical cases. ${ }^{12}$ That the central nervous system (CNS) can be affected early in the course of the infection is well documented. Disturbances of reactions to light of the pupils have been described in cases of early syphilis. ${ }^{3}$ In a recent study abnormal cerebrospinal fluid (CSF) findings were found in $60 \%$ of patients with early (of less than two years duration) syphilis. ${ }^{4}$ Abnormal auditory brain stem responses have been shown to indicate subclinical syphilitic lesions within the CNS. ${ }^{56}$

Voluntary rapid and slow eye movements are performed by the oculomotor system, which involves centres and pathways in the brain. Either supratentorial or infratentorial lesions may disturb the oculmotor function. Oculomotor tests have therefore been used as a sensitive test for lesions in certain locations in the cerebrum, cerebellum, or brain stem. In this study we sought subclinical syphilitic lesions affecting the oculomotor system.

\section{Patients}

\section{CASE 1}

A man aged 33 had a history of alcohol abuse. During routine assessment in a psychiatric clinic positive syphilis serology test results were found as follows: the Wasserman reaction (WR) was positive at a titre of $1 / 60$, the Venereal Disease Research Laboratory (VDRL) test was strongly positive, the fluorescent treponemal antibody absorbed (FTA-ABS) $1 \mathrm{gG}$ test

Address for reprints: Dr Ulf Rosenhall, Department of Audiology, Sahlgren's Hospital, S-413 45 Göteborg, Sweden

Accepted for publication 31 May 1986 was positive at a titre of $1 / 25$, the FTA-ABS IgM test was negative, and the Treponema pallidum immobilisation (TPI) test was positive at a titre of $1 / 160$.

Examination of the CSF showed $3 \times 10^{6}$ mononuclear cells/l. The total protein concentration was $460 \mathrm{mg} / \mathrm{l}$, the albumin quotient (CSF concentration $\times 10^{3} /$ serum concentration) ${ }^{7}$ was $3 \cdot 7$ (normal $<6$ for patients under $45,<7$ for patients over 45 ), and the IgG index (ratio of CSF to serum IgG concentrations/ ratio of CSF to serum albumin concentrations) ${ }^{7}$ was 0.78 (normal $<0.7$ ). Immuno-electrophoresis indicated intrathecal immunglobulin production. The WR was positive at a titre of $1 / 15$, the VDRL and FTA-ABS tests were negative, and the TPI test was positive at a titre of $1 / 10$.

Symptomless neurosyphilis was diagnosed.

\section{CASE 2}

A homosexual man aged 25 who for many years had used intravenous drugs, though he had not used any drugs during the previous decade, developed paranoia. When he was admitted to a psychiatric clinic positive syphilis serology test results were noted as follows: WR positive at a titre of $1 / 480$, VDRL strongly positive, FTA-ABS IgG positive at a titre of $1 / 625$, IgM negative, and TPI positive at a titre of $1 / 5120$.

Examination of the CSF showed $3 \times 10^{6}$ mononuclear cells/ 1 and $9 \times 10^{6}$ polynuclear cells/l. The total protein concentration was $650 \mathrm{mg} / \mathrm{l}$, the albumin quotient $18 \cdot 1$, and the IgG index 0.55 . Immunoelectrophoretic signs of a blood brain barrier lesion were found. There was no intrathecal immunoglobulin production. The WR was positive at a titre of $1 / 15$, the VDRL was negative, and the TPI was positive at a titre of $1 / 80$.

Though the positive syphilis tests in the CSF might have reflected diffusion of antibodies from serum, symptomless neurosyphilis was tentatively diagnosed. 
CASE 3

A man aged 29 from Uganda, who had no history of syphilis or any other skin disease, attended a sexually transmitted disease (STD) clinic. Syphilis serology test results were as follows: the WR was weakly positive, the VDRL positive, the FTA-ABS IgG positive at a titre of $1 / 25$, the FTA-ABS IgM negative, and the TPI was positive at a titre of $1 / 320$.

Examination of the CSF showed $1 \times 10^{6}$ mononuclear cells $/ 1$. The total protein concentration was $386 \mathrm{mg} / \mathrm{l}$, the albumin quotient 3.6 , and the IgG index $\mathbf{0 . 6 2}$. Immunoelectrophoresis of the CSF was normal, and results of the WR, VDRL, and TPI tests were negative.

Latent syphilis or possibly some other treponematosis was diagnosed.

CASE 4

A woman aged 24 from Pakistan had no history of syphilis, but routine screening during pregnancy showed positive syphilis serology as follows: the WR was positive at a titre of $1 / 7 \cdot 5$, the FTA-ABS IgG was positive at a titre of $1 / 125$, the IgM was negative, and the TPI was positive at a titre of $1 / 80$.

Examination of the CSF showed $1 \times 10^{6}$ mononuclear cells $/ 1$. The total protein concentration was $278 \mathrm{mg} /$, the albumin quotient 1.95 , and the IgG index 0.36 . Electrophoresis was normal, and results of the WR, FTA-ABS, and TPI were negative.

Latent syphilis or some other treponematosis was diagnosed.

\section{Methods}

The patients underwent an otoneurological examination, which included pure tone and speech audiometry, auditory brain stem response audiometry, ${ }^{6}$ and oculomotor tests.

For the oculomotor testing a curved ramp equipped with 240 light emitting diodes was placed $120 \mathrm{~cm}$ in front of the patient. The diodes were selectively activated by an encoder that was controlled by a preprogrammed microprocessor. The corneoretinal potentials were detected binocularly by surface electrodes. The signal was amplified and filtered using a $15 \mathrm{~Hz}$ lowpass filter, and was registered by a Siemens-Elema Mingograph 34 ink jet recorder.

For the saccade test the gaze angles $20^{\circ}, 40^{\circ}$, and $60^{\circ}$ were used. The saccades were horizontal and nonpredictable. Seven to eight saccades in each direction were recorded for each gaze angle. The maximum saccadic velocity and the accuracy of the saccades were measured.

To test linear horizontal smooth pursuit eye movements a light spot was moved over the ramp with the velocities $10 \% \mathrm{~s}, 20 \% \mathrm{~s}, 30 \%$, and $40 \%$ s. The mean velocity gain (the ratio between the velocity of the eyes and the target velocity) was estimated. The mean speed of the smooth pursuit eye movements when the corrective saccades had been excluded was used to calculate the gain. The mean gain from six tracking eye movements in each direction was calculated for each target velocity.

A group of 55 healthy people (28 women, 27 men, mean age 32.6 (range 20 to 50 ) years) was used for comparison. The control mean ( $2 \mathrm{SD}$ ) for all variables studied was considered to be the normal performance.

Sedative drugs were not given for one to two days before testing.

\section{Results}

\section{SACCADES}

The velocity of the saccades was normal in all four patients. In two instances (cases 1 and 2) the voluntary horizontal saccades were appreciably hypometric (fig 1). The saccadic precision was reduced only for the

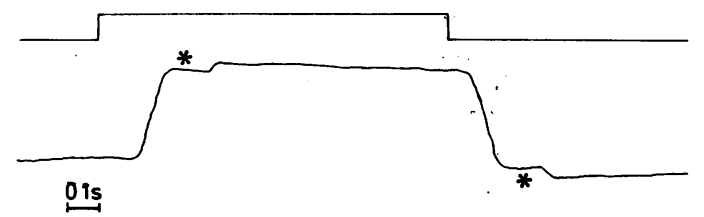

FIG 1 (Case 1) Horizontal, voluntary $60^{\circ}$ saccades (lower recording). Upper recording represents the target movements. The first saccade, which is directed upwards on the graph, is right-beating, and the second one is directed to the left. Both saccades are slightly hypometric. The amplitude of each of the main saccades was insufficient and a corrective saccade (*) was added to the main saccade to make it possible for the gaze to reach the target.

gaze angles $20^{\circ}$ and $60^{\circ}$. The saccades of case 1 that were directed to the right and generally those of case 2 directed to the left were inaccurate. The other two patients (cases 3 and 4) had occasional hypermetric saccades (fig 2), but the mean accuracy of their saccades was normal.

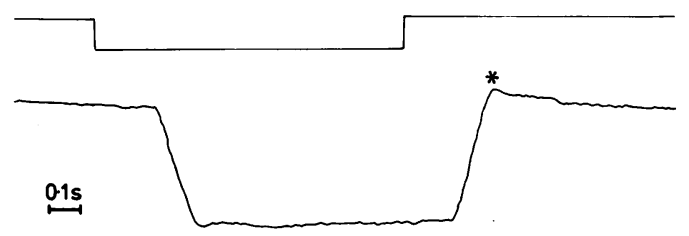

FIG 2 (Case 3.) Two $60^{\circ}$ saccades (lower recording), the first directed to the left and the second to the right. The first was normal, the second was hypermetric. The amplitude of the second saccade was too large, which resulted in an overshoot $(*)$. 
SMOOTH PURSUIT EYE MOVEMENTS

Three of the four patients had abnormal smooth pursuit eye movements. The abnormality consisted of reduced maximum smooth pursuit velocity and an increased number of superimposed corrective saccades. The overall result was a tracking eye movement in which the ordinary smooth pursuit was interrupted by saccades to enable the gaze to follow the target (fig 3).

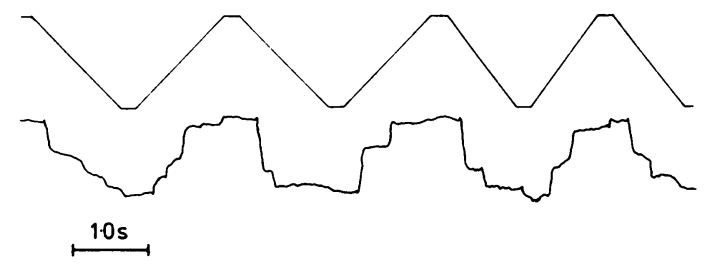

FIG 3 (Case 4.) Smooth pursuit eye movement test (lower recording). Upper recording represents the target movements. The velocity was first $30 \%$ and then $40 \%$. The smooth pursuit eye movements (lower recording) were insufficient to track the target and numerous corrective saccades were added, which resulted in a step like tracking eye movement.

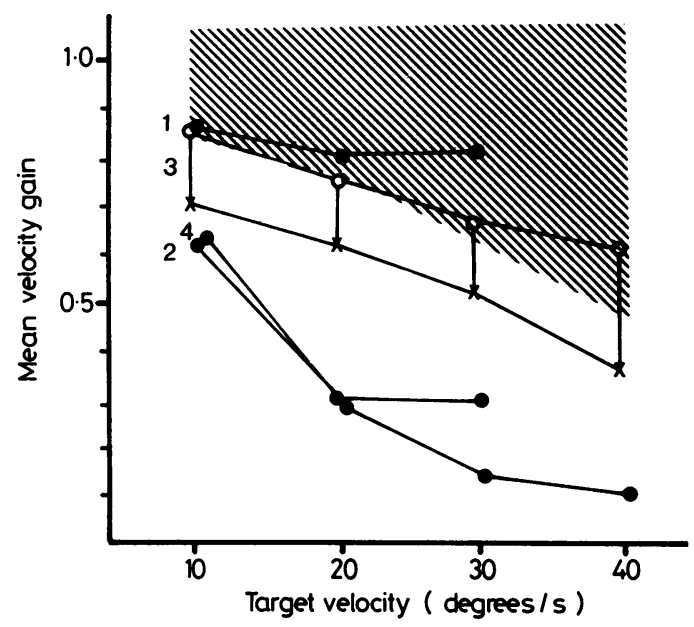

FIG 4 Diagram showing mean velocity gain of smooth pursuit eye movements on the $X$ axis and target velocity on the $Y$ axis. Velocity gain was ratio between velocity of the eyes performing a smooth pursuit and velocity of the moving light spot (target). Shaded area represents mean (2 SD) performance of control group for the four different target velocities used $\left(10 \% \mathrm{~s}, 20 \% \mathrm{~s}, 30 \%\right.$ and $\left.40^{\circ} / \mathrm{s}\right)$. Individual performance of the four patients with syphilis is shown thus: combined velocity gain in both directions for patients (cases 1, 2, and 4) who had symmetrical smooth pursuits( $\bullet$ ), asymmetrical performance (case 3) with normal smooth pursuits to the right (o) and abnorinal smooth pursuits to the left $(\times)$. Cases 2 and 4 had severely abnormal smooth pursuit eye movements with noticeably reduced velocity gain for the target velocity $20 \%$ or more.
Figure 4 shows the mean velocity gain of each patient. Two (cases 2 and 4) had severely altered smooth pursuits, especially for the target velocity of $20 \%$ or more. These patients had symmetrical performance in both directions. Another patient (case 3) had moderately abnormal smooth pursuits. He had asymmetrical performance with normal smooth pursuits to the right but abnormal velocity gain to the left for all target velocities studied.

\section{AUDIOLOGICAL TEST RESULTS}

Three of the four patients had normal auditory brain stem response recordings. One (case 2) had abnormal brain stem responses. In this case the latency of wave $\mathrm{V}$ was $5.5 \mathrm{~ms}$ for the right ear and $5.9 \mathrm{~ms}$ for the left ear. The corresponding values for the I-V interpeak latency were $4.1 \mathrm{~ms}$ for the right ear and $4.5 \mathrm{~ms}$ for the left ear. The latter value was pathological, as was the interaural time difference for wave $\mathrm{V}$ and the $\mathrm{I}-\mathrm{V}$ interpeak latency $(0.4 \mathrm{~ms})$.

Three of the four patients had normal hearing capacity in both ears. One (case 4) had sensorineural hearing loss affecting the low and middle frequencies of the left ear. This unilateral hearing loss was located in the cochlea according to auditory brain stem response, impedance audiometry, and speech audiometry. She had also had attacks of vertigo, and the clinical picture as well as the audiological test results indicated that she had Menière's syndrome.

\section{Discussion}

The incidence of syphilis has decreased dramatically in Sweden during the past two years. This probably reflects changed sexual habits of homosexuals who have become aware that casual sexual relations might lead to the acquired immune deficiency syndrome (AIDS). For this reason only a small number of patients could be examined in the present study, and this fact makes it difficult to draw extensive conclusions from the results presented here. It is, however, remarkable that all four patients studied had some kind of oculomotor disturbance.

Three of the patients had alterations of the smooth pursuit eye movements, two profoundly and one more moderately. Smooth pursuits can be affected by lesions located in various parts of the brain. Supratentorial lesions may cause alterations of smooth pursuit eye movements if they are situated in the frontoparietal region $^{7-9}$ or in the occipital lobe. ${ }^{10}$ Infratentorial lesions, situated in the brain stem or the cerebellum, very often cause disturbance of smooth pursuits. ${ }^{811-14}$ There are, however, some other possible explanations for abnormal smooth pursuits with reduced velocity gain. In the present study we therefore tried to eliminate irrelevant factors, such as the influence of drugs $^{15}$ and defective attention. ${ }^{16}$ 
Two of the patients studied here (cases 1 and 2) had slightly abnormal horizontal voluntary saccades; the accuracy of the saccades was slightly pathological, but the saccadic velocity was normal. Such findings can be consistent with either a supratentorial or a cerebellar lesion. ${ }^{8}$ One of the patients (case 1 ) was an alcoholic. As cerebellar ataxia and central pontine myelinolysis can be observed in patients with severe alcoholism, the correlation between saccadic hypometria and syphilis was not confirmed in this case, though the auditory brain stem response, which is generally abnormal in central pontine myelinolysis ${ }^{17}$ was normal.

One patient (case 2) had profoundly deranged smooth pursuit eye movements as well as slightly hypometric saccades and abnormal auditory brain stem responses. These findings are clearly consistent with a pontocerebellar dysfunction. Moreover this patient had findings of the CSF that indicated neurosyphilis.

Another patient (case 4) also had severely abnormal smooth pursuit eye movements, but she had basically normal saccades and also normal auditory brain stem responses. The smooth pursuit eye movements test was nevertheless indicative of a disorder of the CNS, but its location was probably not in the brain stem. This patient also had Menière's syndrome in one ear. The simultaneous presence of treponematosis and Menière's syndrome could be coincidental, but it should be emphasised that syphilis can cause Menière like conditions. ${ }^{18}$

One patient (case 1) had hypometric saccades but normal smooth pursuits and auditory brain stem responses. This pattern of abnormality could possibly be explained by a frontal lobe lesion. ${ }^{19}$ This patient had only a minor oculomotor disturbance despite the CSF findings, which clearly indicated neurosyphilis.

Another patient (case 3 ) had moderately pathological smooth pursuits in one direction only, but normal saccades and auditory brain stem responses. This pattern can also be consistent with a lesion of the CNS, but the location of such a possible lesion could not be identified.

We have reported previously on the asymptomatic effects of early syphilis on the CNS, which can be detected by auditory brain stem responses and analysis of the CSF. ${ }^{56}$ In the present study we used refined methods, which can detect very discrete lesions of the CNS. The findings presented here strongly support our earlier observations on neurological alterations caused by syphilis. According to the results of this study, occult brain dysfunction might be even more common in people with syphilis than has previously been assumed.

\section{References}

1. Hooshmand H, Escobar MR, Kopf SW. Neurosyphilis. A study of 241 patients. JAMA 1972;219:726-9.

2. Joyce-Clarke N, Moltena ACB. Modified neurosyphilis in the Cape Peninsula. S Afr Med J 1978;53:10-4.

3. Braitsev AV, Kochetkov VD. Fluorescent examinations of eye pupils and pupil reactions in early forms of syphilis. Vestn Dermatol Venerol 1968;42:47-51.

4. Löwhagen G-B, Andersson M, Blomstrand C, Roupe G. Central nervous system involvement in early syphilis. Part $I$. Intrathecal immunoglobulin production. Acta Derm Venereol (Stockh) 1983;63:409-17.

5. Rosenhall U, Roupe G. Auditory brain-stem responses in syphilis. British Journal of Venereal Diseases 1981;57:2415.

6. Löwhagen G-B, Rosenhall U, Andersson M, Blomstrand C, Lindholm L, Roupe G. Central nervous system involvement in early syphilis. Part II. Correlation between auditory brainstem responses (ABR) and cerebrospinal fluid abnormalities. Acta Derm Venereol (Stockh) 1983;62:530-5.

7. Tibbling G, Link H, Öhman S. Principles of albumin and IgG analyses in neurological disorders. I. Establishment of reference values. Scand J Clin Lab Invest 1977;37:385-90.

8. Troost BT, Daroff RB, Weber RB, Dell'Osso LF. Hemispheric control of eye movements. II. Quantitative analysis of smooth pursuit in hemispherectomy patients. Arch Neurol 1972; 27:449-52.

9. Baloh RW, Honrubia V, Sills A. Eye-tracking and optokinetic nystagmus. Results of quantitative testing in patients with welldefined nervous system lesions. Ann Otol Rhinol Laryngol 1977;86:108-14.

10. Pyykkö I, Dahlen A-L, Schalén L, Hindfelt B. Eye movements in patients with speech dyspraxia. Acta Otolaryngol (Stockh) 1984;98:481-9.

11. Hartje W, Kerschensteiner M. Eine quantitative Analyse der sakkadierten Folgebewegungen der Augen bei einseitigen Hemisphärenschädigungen. Zeitschrift für Neurologie 1973;203:229-310.

12. Corvera J, Torres-Courtney G, Lopez-Rios G. The neurological significance of alterations of pursuit eye movements and the pendular tracking test. Ann Otol Rhinol Laryngol 1973;82:855-67.

13. Dichgans J, Jung R. Oculomotor abnormalities due to cerebellar lesions. In: Lennerstrand G, Bach-y-Rita $P$, eds. Basic mechanisms of ocular motility and their clinical implications. Oxford: Pergamon Press, 1975:281-98.

14. Wennmo C, Hindfelt B. Eye movements in patients with brain stem disorders. Acta Otolarygol (Stockh) 1980;90:230-6.

15. Schalén L, Henriksson NG, Pyykkö I. Quantification of tracking eye movements in patients with neurological disorders. Acta Otolaryngol (Stockh) 1982;93:387-95.

16. Esser J, Brandt T. Pharmakologisch verursachte Augenbewegungsstörungen - Differentialdiagnose und Wirkungsmechanismen. Fortschritte der Neurologie, Psychiatrie 1983;51:41-56.

17. Bickford RG, Klass DW. Eye movement and electroencephalogram. In: Bender MB, ed. The oculomotor system. New York: Harper and Row, 1964: 293-302.

18. Rosenhamer HJ, Silfverskiöld B. Slow tremor and delayed brainstem auditory evoked responses in alcoholics. Arch Neurol 1980;37:293-6.

19. Pulec JL. Symposium on Menière's disease. I. Menière's disease: results of a two and one-half year study of etiology, natural history and results of treatment. Laryngoscope 1972;82:1703-15.

20. Pyykkö I, Schalén L. Evaluation of tests for the detection of central vestibular lesions. In: Oosterveld WJ, ed. Otoneurology. New York: John Wiley and Sons Ltd, 1982. 